\title{
Trends in fragmentation and connectivity of Paspalum quadrifarium grasslands in the Buenos Aires province, Argentina
}

\author{
Marcelo L Gandini ${ }^{\text {Corresp., }}{ }^{1,2}$, Bruno D Lara ${ }^{1,3}$, Laura B Moreno ${ }^{1}$, Maria A Cañibano ${ }^{1}$, Patricia A Gandini ${ }^{4,5}$ \\ 1 Facultad de Agronomía, Universidad Nacional del Centro de la Provincia de Buenos Aires, Azul, Buenos Aires, Argentina \\ ${ }^{2} \mathrm{CIC}$ (Comisión de investigaciones Científicas de la provincia de Buenos Aires), Azul, Buenos Aires, Argentina \\ 3 CONICET (Comisión Nacional de investigaciones Científicas y Técnicas de Argentina), Azul, Buenos Aires, Argentina \\ 4 Unidad Académica Caleta Olivia, Universidad Nacional de la Patagonia Austral, Puerto Deseado, Santa Cruz, Argentina \\ 5 CONICET (Comisión Nacional de investigaciones Científicas y Técnicas de Argentina), Puerto Deseado, Santa Cruz, Argentina \\ Corresponding Author: Marcelo L Gandini \\ Email address: mgandini@faa.unicen.edu.ar
}

Background. Despite its wide distribution worldwide, only $4.6 \%$ of temperate grasslands are included within systems of protected areas. In Argentina, this situation is even more alarming: only $1.05 \%$ is protected. The study area (central area of the southern Salado River basin) has a large extent of grasslands of Paspalum quadrifarium (Pq) which has been target since the middle of the last century of a variety of agricultural management practices including fire burning for cattle grazing.

Methods. Five binary images of presence-absence data of Pq from a 42-year range (1974-2016) derived from a land cover change study were used as base data. Morphological Spatial Pattern Analysis (MSPA), Morphological Change Detection (MCD) and Network Connectivity Analysis (NCA) were performed to the data using Guidos Toolbox (GTB) for the estimation of habitat and connectivity dynamics of the Pq patches (fragments).

Results. A loss of the coverage area and habitat nuclei of this grassland was observed during the study period, with some temporal oscillation but no recovery to initial states. Additional drastic reduction in connectivity was also evident in resulting maps. The number of large Pq grassland fragments ( $>50$ ha) decreased at beginning of the study period. Also fragmentation measured as number of components (patches) was higher at the end of the study period. The Pq pajonal nuclei had their minimum representativeness in 2000, and recovered slightly in area in 2011, but with a significant percentage increase of smaller patches (=islets) and linear elements as bridges and branches. Large corridors (mainly edge of roads) could be observed at the end of the study period, while the total connectivity of the landscape pattern drops continuously. Statistics of links shows mean values decreasing from 1974 to 2016. On the other hand, maximum values of links decreased up to $19 \%$ in 2011 , and recovered to a $54 \%$ of their original value in 2016.

Discussion. $\mathrm{Pq}$ fragmentation and habitat reduction could have an impact on the ecosystem functioning and the mobility of some species of native fauna. The connecting elements of the landscape were maintained and/or recovered in percentage in 2011 and 2016. This fact, although favoring the dispersion of the present diversity in the habitat nuclei could cause degradation by an edge effect. Part of the area has the potential to be taken as an area of research and as an example of livestock management, since it is the one that would most preserve the biodiversity of the Pq environment. On the methodological side, the use of a proved tool as GTB is useful for monitoring dynamics of a grassland-habitat fragmentation. 


\section{Trends in fragmentation and connectivity of Paspalum quadrifarium}

\section{2 grasslands in the Buenos Aires province, Argentina}

\section{Marcelo L Gandini ${ }^{1,3}$ Bruno D Lara $^{1,2}{ }^{2}$ aura B Moreno $^{1}$ María A Cañibano ${ }^{1}$ Patricia A}

5 Gandini ${ }^{2,4}$

$6 \quad{ }^{1}$ Facultad de Agronomía-UNCPBA- Azul, Buenos Aires, Argentina.

$7 \quad{ }^{2}$ CONICET (Comisión Nacional de investigaciones Científicas y Técnicas, Argentina)

$8 \quad{ }^{3} \mathrm{CIC}$ (Comisión de investigaciones Científicas de la provincia de Buenos Aires, Argentina)

$9 \quad{ }^{4}$ UNPA (Universidad Nacional de la Patagonia Austral) Santa Cruz, Argentina

11 Corresponding author:

12 Marcelo Gandini ${ }^{1}$

13 Email adress:mgandini@faa.unicen.edu.ar 


\section{ABSTRACT}

Background. Despite its wide distribution worldwide, only $4.6 \%$ of temperate grasslands are included within systems of protected areas. In Argentina, this situation is even more alarming: only $1.05 \%$ is protected. The study area (central area of the southern Salado River basin) has a large extent of grasslands of Paspalum quadrifarium (Pq) which has been target since the second half of the last century of a variety of agricultural management practices including fire burning for cattle grazing.

Methods. Five binary images of presence-absence data of Pq from a 42-year range (1974-2016) derived from a land cover change study were used as base data. Morphological Spatial Pattern Analysis (MSPA), Morphological Change Detection (MCD) and Network Connectivity Analysis (NCA) were performed to the data using Guidos Toolbox (GTB) for the estimation of habitat and connectivity dynamics of the Pq patches (fragments).

Results. A loss of the coverage area and habitat nuclei of this grassland was observed during the study period, with some temporal oscillation but no recovery to initial states. Additional drastic reduction in connectivity was also evident in resulting maps. The number of large Pq grassland fragments (>50 ha) decreased at beginning of the study period. Also fragmentation measured as number of components (patches) was higher at the end of the study period. The Pq pajonal nuclei had their minimum representativeness in 2000, and recovered slightly in area in 2011, but with a significant percentage increase of smaller patches (=islets) and linear elements as bridges and branches. Large corridors (mainly edge of roads) could be observed at the end of the study period, while the total connectivity of the landscape pattern drops continuously. Statistics of links shows mean values decreasing from 1974 to 2016. On the other hand, maximum values of links decreased up to $19 \%$ in 2011 , and recovered to a $54 \%$ of their original value in 2016.

Discussion. Pq fragmentation and habitat reduction could have an impact on the ecosystem functioning and the mobility of some species of native fauna. The connecting elements of the landscape were maintained and/or recovered in percentage in 2011 and 2016. This fact, although favoring the dispersion of the present diversity in the habitat nuclei could cause degradation by an edge effect. Part of the area has the potential to be taken as an area of research and as an example of livestock management, since it is the one that would most preserve the biodiversity of the Pq environment. On the methodological side, the use of a proved tool as GTB is useful for monitoring dynamics of a grassland-habitat fragmentation. 


\section{INTRODUCTION}

47 The loss of habitat and the fragmentation of ecosystems are one of the main threats to the conservation of biodiversity worldwide (Fahrig 2003, Hobbs \& Yates 2003, Henle et al 2004, Wilson et al. 2016, Woods et al. 2016). In Argentina, the conversion of natural ecosystems to agricultural lands has consequences such as the loss of habitat and biodiversity, the alteration of biotic interactions and biogeochemical processes (water cycles, carbon and nutrients), the reduction of the capacity to provide ecosystem services and the transformation of the landscape (Herrera et al., 2012; Volante et al., 2012; Gandini et al. 2014). In this way, and given the impact anthropogenic activities on natural systems (Vitousek et al., 1997), understanding if and how biodiversity recovers from disturbances is an important focus of ecology and conservation biology.

Despite its large distribution worldwide, only $4.6 \%$ of temperate grasslands are included within national protected area systems (Baldi et al 2017). In Argentina, this situation is even more alarming since only $1.05 \%$ is protected (Bilenca \& Miñarro 2004). The underestimation of the productive value of these natural grasslands starts from the difficulty of objectively visualizing

61 the goods and ecosystem services that they provide.

62 A characteristic type of grassland landscape in the Salado river basin is the "pajonal" of

63 Paspalum quadrifarium also known as Paspaletum (Vervoorst 1967). It represents one of the 64 twelve plant communities identified in this area. It is a type of grassland characterized by a marked abundance of $\mathrm{P}$. quadrifarium, a grass that can grow into dense tufts reaching 1 to $1.50 \mathrm{~m}$ high (Frangi 1986), intermingled with various companion species in different proportions.

67 Paspaletum is characterized by its distribution in a wide range of topographies (Lara \& Gandini 68 2013a) forming different vegetation units (Perelman et al. 2003; Lara \& Gandini 2013b). 
69 Paspaletum, like other pampa's grasslands have been under fire and grazing disturbance for a

70 long time. Since the introduction of domestic livestock by European settlers and almost without

71 interruption, this grassland has been managed by changing their coverage and land use in

72 different ways (Foley et al. 2005, Vazquez et al. 2012). Fire burning is currently used in the

73 winter-spring period with the aim of increasing net productivity and thus livestock receptivity

74 (Laterra 2003). In this way, the interaction of fire with cattle grazing led to deep changes that can

75 be seen across scales of analysis (Herrera et al 2009; Lara \& Gandini 2011).

76 Ecologists distinguish between a particular disturbance event -like an individual storm or fire-

77 and the disturbance regime that characterizes a landscape (Turner \& Gardner 2015, White and

78 Jentsch 2001). The current increase in disturbances due to agricultural and livestock pressure in

79 the region (Cañibano et al., 2004; Vázquez et al., 2012) is a discouraging scenario leading to the

80 substitution of natural grass cover. However, Paspaletum (ecological community of Paja

81 Colorada - Paspalum quadrifarium) remnant patches still persist in the centre of Buenos Aires

82 province. These patches were maintained as pasture sites in good state of conservation (Herrera

83 et al., 2009).

84 According to studies of "Fundación Vida Silvestre Argentina" -an environmental NGO-, these

85 sites were classified as Valuable Grassland Areas (PVAs), given their importance as a source of

86 great native animal diversity and the numerous ecosystem services they provide (Bilenca and

87 Miñarro 2004).

88 Human encroachment on the environment through resource extraction and urban expansion have

89 led to fragmentation (Maguire et al. 2016), with consequences for biodiversity (Chapin et al.

90 2000), ecosystem processes (Díaz \& Cabido 2001, Harrington et al. 2010) and the ecosystem

91 services that they are supporting (Mitchell et al, 2014). Fahrig (2003) considered fragmentation 
92 as one of the most damaging threats to biodiversity conservation in recent times because the

93 population viability in fragmented landscapes depends to a large extent on the structural and

94 functional integrity of the landscape. In this context, it is necessary to carry out studies that allow

95 analysing the trends of change at landscape scale in these habitat fragments, and their

96 connections to implement management and conservation strategies in areas of high regional

97 ecological importance and vulnerability.

98 The sustainable management of fragmented landscapes will depend on understanding the spatial

99 ecology of the ecosystem services needed over the long-term (Maguire et al. 2016). In terms of

100 the functional integrity of ecosystems, landscape connectivity is considered one of the key

101 properties to maintain biodiversity. Landscape connectivity is defined as the degree to which

102 landscape facilitates the movement of species and other ecological flows (Taylor et al., 1993). It

103 is considered a key aspect to take into account for biodiversity conservation efforts around the

104 world and one of the best responses to counteract the negative effects of habitat fragmentation

105 and to facilitate species adaptation to changes in their natural habitats (Crooks and Sanjayan

106 2006).

107 Improved landscape connectivity is becoming regarded as a viable management strategy to

108 maintain biodiversity, ecosystem functions, and services (Ziter et al. 2013). In a part of the study

109 area -the Salado River basin- the habitat fragmentation pattern has been reported to have

110 increased considerably in the last 40 years (Lara \& Gandini 2014), thus becoming one of the

111 major environmental problems in the basin.

112 Guidos Toolbox (GTB) is a free software available for analysing the structural and functional

113 integrity of the landscape in terms of conservation. Particularly Morphological Spatial Pattern

114 Analysis (MSPA) and Network Connectivity Analysis (NCA) can help researchers to build 
115 hypothesis about this issue. The generic setup of MSPA has been used to identify and map forest

116 patterns, both structural (Vogt et al. 2007a) and functional (Vogt et al. 2007b), to identify key

117 connectors for habitat suitability (Saura et al., 2011), for riparian corridor conservation studies

118 (Clerici \& Vogt, 2013), or evaluation of the US green infrastructure (Wickham et al., 2010) up to

119 classifying zooplankton (Schmid et al, 2016). A unique feature of MSPA is the automatic

120 detection of connecting pathways between core areas of image objects. Once found, the logical

121 next point of interest is to rank those detected pathways with respect to the relative importance of

122 each component, node and link in a given network. This task could be achieved by applying

123 concepts and metrics of graph theory (Saura \& Torné (2009). Compared to typical Fragstat

124 indices (Lara \& Gandini 2014), we consider that MSPA-exclusive information on core-areas,

125 islets and connecting pathways could be the best way to show the changes along time.

126 Complementarily, the direct relationship between MSPA and network theory presents NCA as

127 the simplest way to explain the trends we search for. In addition, within GTB it is also possible

128 to perform a calculation of the Equivalent Connected Area (ECA) as a summary of overall

129 connectivity, because it has area units, it is easier to interpret and has a more usable range of

130 variation (Saura et al. 2011)

131 In this work the MSPA and NCA in GTB were applied to a remote sensing classification of

132 Landsat images in order to analyze the 42-year temporal change in the habitat fragments of Pq

133 grasslands (Paspalum quadrifarium).

\section{MATERIALS \& METHODS}

\section{Study Area}

136 The study was carried out in the Flooding Pampa and Inland Pampa areas of the Salado River

137 basin, in the Buenos Aires province (Argentina), covering mainly two different agroecological 
138 zones, the "Flooding and Inland Pampas" (Figure 1). This square area contains most of the

139 population of $\mathrm{Pq}$ and thus was considered as representative of the ecological community of

140 interest (Gandini et al., 2014) and their conservation status.

141 Data acquisition, pre-processing and land cover classification

142 A series of five Landsat images (path 225, row 85) for the years 1974 (MSS sensor), 1988 (TM

143 sensor), 2000 (ETM + sensor), 2011 (TM sensor) and 2016 (OLI sensor) was used. The digital

144 numbers (DN) were converted to reflectance (except for the thermal band) according to Chander

145 et al. (2009), and the reflectance values were then adjusted for atmospheric scattering using the

146 Improved Dark Object Subtraction method by Chavez (1996).

147 In accordance with previous reports (Herrera et al., 2009, Lara and Gandini, 2013b), the initial

148 land cover types used were: pajonal, short-grass matrix, pastures, crops and water bodies. To

149 identify the land cover types, supervised classifications were employed using the maximum

150 likelihood algorithm ( $\mathrm{Lu}$ and Weng 2007). The classifications were performed using all

151 reflective Landsat bands; for 1974: MSS4, MSS5, MSS6 and MSS7; for 1988 and 2011: TM1,

152 TM2, TM3, TM4, TM5 and TM7; for 2000: $\mathrm{ETM}+1, \mathrm{ETM}+2, \mathrm{ETM}+3, \mathrm{ETM}+4, \mathrm{ETM}+5$

153 and ETM + 7, and for 2016, Bands 2, 3, 4, 5, 6 of OLI Sensor. The thermal bands of platforms

154 were discarded.

155 For 1988, the training sites were located by visual interpretation on 44 aerial infra-red

156 photographs (scale 1: 20,000) taken in 1988 summer, following criteria such as texture, shape

157 and colour (Chuvieco,2010). For 2011 and 2016, the control points were selected using a global

158 positioning system (GPS) in the field within relatively homogeneous areas. For 1974 and 2000,

159 the training sites were selected by visual analysis following the medium spectral signature for

160 each land cover type and using areas with similar spectral characteristics - over land cover 
161 remained unchanged- (Chuvieco, 2010; Schulz et al., 2010).

162 Classification results were filtered using a 7 x 7 median filter to remove isolated pixels. Later,

163 the MSS classification (1974) was re-sampled to a $30 \times 30 \mathrm{~m}$ pixel size to allow multi-temporal

164 comparison with the rest of the series.

165 The accuracy of the classification maps was assessed with the use of quantity disagreement and

166 allocation disagreement (Pontius and Millones, 2011). These indices are more useful and simpler

167 than standard Kappa (Congalton, 1991) and allowed us to focus on two components of

168 disagreement between maps and reference points in terms of the quantity and spatial allocation

169 of the land cover types. Quantity disagreements, and not allocation disagreement, were

170 particularly taken into consideration to assess classification quality since the main aim of this

171 work was focused on regional changes and not pixel-to-pixel changes (Keller and Smith 2014).

$172 \underline{M S P A}$ and NCA

173 Pajonal fragments were identified based on these classifications, and binary Pajonal presence-

174 absence maps were created. These binary maps of 1974, 1988, 2000, 2011 and 2016 were

175 analyzed using MSPA within GTB (Vogt \&Riitters, 2017).

176 MSPA Parameters were chosen taking into account field measurements where it was shown that

177 patches of approximately 1 ha (3 Landsat pixels) may contain maximum diversity of plant

178 species, and that it also depends on the distance and connectivity between the patches. In this

179 way, an edge width of 3 pixels and the standard foreground connectivity of 8 was chosen.

180 Besides this, we divided core-areas into small/medium/large using the default settings of 1000

181 and 4600 pixels in order to consider the size of cattle ranches and the type of megafauna present

182 in the study area, and also to use this distinction to visually highlight the changes over time.

183 At the same time, a comparative analysis of trends in landscape connectivity was carried out, 
184 evaluating the variations in the networks and connectivity of the patches of pajonal. The analysis

185 was performed considering each set of connected patches as a single landscape element. In this

186 way the size of the elements varied as the patches were fragmented and disconnected by the

187 effect of the livestock management (fire and grazing disturbance).

188 ECA was calculated via GTB . ECA measures the overall structural connectivity between the set

189 of network components (Core + bridges but excluding all the other MSPA classes) accounting

190 for their area and the number of nodes and links within each component.

191 Because of this definition, ECA provides us a measure which is not species-specific and as such

192 an independent overall measure of connectivity (Saura et al. 2011).

193 On the other hand, spatio-temporal changes were analyzed by Morphological Change Detection

194 (MCD) within GTB with a focus on neglecting spurious changes and providing essential change

195 in areas of loss and gain only (Seebach et al. 2013).

\section{RESULTS}

197 The supplemental material provides a complete set of base images, and resulting images of

198 Classification (Pq mask), MSPA and connectivity for the 5 analyzed years. To simplify

199 interpretation, only the start and end years of the observation time period (1974-2016) are shown 200 in the main body of the text.

\section{Image classification of land cover}

202 Classification error issues are shown in Table 1. Good thematic accuracies for Pq were obtained, 203 and the separation of overall disagreement into two components was used to learn about sources 204 of error and give guidance on how to improve each classification (Pontius and Millones, 2011).

205 Fragmentation, habitat loss and trends in connectivity

206 Table 1 summarizes the results of MSPA and Connectivity numerically. The small cores had a 
207 rapid fall of around 25\% between 1974 and 1988, and then kept oscillating between values that

208 never reached the initial stage. A similar behaviour was found for medium cores, which dropped

209 by approximately $50 \%$ in the same time frame. The main change was found for large cores with

210 a decrease of more than $60 \%$ in 1988 , followed by a transient slight increase in 2000 , and

211 continued with the decreasing trends in 2011 and 2016.

212 The edges tend to decay oscillating until reaching a minimum value of 8.61 in 2011 and then

213 recover slightly in 2016. Islets and perforations show a similar trend like cores.

214 Regarding the "linear" elements (loops, bridges and branches) a tendency to prevail in time is

215 observed although the bridges are lost more quickly reaching low values from 2000.

216 The foreground area, reached a minimum value in 2011, recovering slightly in 2016 (Table 1, see

217 also Figures 2 and 3), although not achieving the previous values of 1974, 1988 or 2000.

218 Statistics of links showed mean values decreasing from 1974 to 2016, and maximum values

219 recovering to a $50 \%$ of their original value. In terms of connectivity, the average number of links

220 declined rapidly between 1974 and 1988, tending to decrease during the entire study period,

221 although the percentage in relative ECA increased at a high rate and there was a minimum in

222 2011, indicating the dynamics of the patches.

223 Fragmentation measured as number of components (patches) resulting from habitat pressure was

224 higher in 2011 and 2016 (Table 1). This observation agrees with MSPA data, in which the 225 pajonal nuclei had their minimum representativeness in 2000 , and recovered by 2011 , with a

226 significant percentage increase in the small patches (=islets). While edges and loops remained 227 relatively stable, the linear elements (bridges and branches) increased their representativeness

228 (Table 1, MSPA; see also Figure 2 and 3). In 2016, larger corridors (mainly edges of roads)

229 could be observed while the total connectivity of the landscape pattern remains low (Table 1; 
230 connectivity and Figures 4 and 5) in terms of mean and median connectivity after 1988 and

231 percentage of relative ECA after 2011.

232 Temporal variation of relative ECA showed the dynamics of the fragmentation process in the

233 study area: from an initial value of $28 \%$, almost doubled in only 14 years (1988). In successive

234 years, the connectivity and ECA decreases to a minimum in 2011, followed by a slight increase

235 in 2016. A visual comparison between connectivity maps (Figures 4 and 5), showed spatially the

236 relevance of the change in connectivity and network size.

237 Figure 6 shows the result of MCD applied between 1974 and 2016. A foreground loss of $43 \%$ is

238 explained mainly as an internal foreground loss (elasticity 1.10575). In general, it could be

239 observed a high Pq loss area and some gain areas in the West side of map. Only a zone in the

240 south-west of the study area remains less changed in Foreground.

\section{DISCUSSION}

242 This work showed that the habitat patches of Pq have undergone deep transformations since

2431974 in agreement with the findings of Lara \& Gandini (2014). They reported that the original

244 landscape matrix of Pq was replaced by other subordinate communities, e.g. Short-Grasses

245 Matrix.

246 The variations in the size and connectivity of the patches of Pq were significant in the study

247 period (1974-2016). The major effects were the habitat fragmentation and patch number and size

248 reduction leading to connectivity loss. In terms of fragmentation, there was a true fragmentation,

249 and also a slight habitat loss, determined by: a) A high trend to lower the patch size and the

250 connectivity and b) An increase of linear elements at the end of the study period. Although the

251 connecting elements of the landscape had maintained and/or recovered in percentage, favoring

252 the dispersion of the present diversity in the habitat nuclei and preserving patches as breakup 
253 centers, this fact could be related with a degradation by edge effect.

254 Slight structural recovery measured by ECA\% and in terms of area could be seen at the end of

255 the study period mainly for the maintenance of linear structures such as bridges. Similar to

256 fragmentation, connectivity is not a good or bad issue, and it strongly depends on the selected

257 species we analyse but a negative trend is pointing at least some habitat quality loss for a species.

258 Statistics of links as mean, median and maximum, shows also the trends of connectivity and

259 habitat losses. Means decreased continuously, and median values increase in 2016 along with

260 the maximum number of links indicating a possible partial recovery.

261 The effect on diversity could be more important when considering that habitat patches form a

262 "network" and that they are not connected to each other (Maguire et al. 2016). This loss of

263 connectivity is clearly evidenced comparing figure 4 vs figure 5 .

264 Although the connectivity (median values) of 1988 is maintained with respect to 1974, relative

265 ECA increases to double. This would indicate that the dynamics of fragmentation occurred

266 rapidly, starting with a decrease in the size of the patches, followed by a loss of connectivity. The

267 ECA as calculated via GTB looks at the overall structural connectivity between a set of network

268 components (Core + bridges of Pq) but excluding all the other MSPA classes, accounting for

269 their area, number of nodes and links within each component. ECA is defined as the size that a

270 single patch of habitat (maximally connected) should have in order to provide the same value of

271 IIC (integral index of connectivity) or PC (Probability of Connectivity) than the actual habitat

272 pattern in the landscape (Saura et al. 2011). With this definition, ECA provides an non species-

273 specific measure and as such an independent overall measure of connectivity.

274 Within the framework of environmental conservation, monitoring these environments and

275 conducting further research on their impact on biodiversity are deemed necessary. The 
276 methodological approach used in this work, like that employed by Wickham et al. (2010), was

277 used to identify and classify the morphological types of fragmentation, focusing on the dynamics

278 of habitat availability and also to recognize the temporal variation of the landscape connective

279 elements.

280 This research opens up the need to face a short-term research about the minimum size of pajonal

281 fragments that preserve different ecosystem services, maintaining their biodiversity components

282 and structure in an acceptable status. Having this information, it is possible to propose

283 sustainable management plans for the livestock agro-ecosystems of the region.

284 The results obtained with MCD also show that the community of $\mathrm{Pq}$ (managed as forage source

285 in this case) tends to change spatially in a very dynamic way as shown clearly in Figure 6. Zones

286 without change are very scarce during the study. Only a portion of the study area in South-West

287 remains substantially unchanged in Foreground. This area has the potential to be taken as an area

288 of research and also as example of livestock management, since it is the one that would most

289 preserve the biodiversity of the Pq environment.

290 On the methodological side, the generic design of the fragmentation assessment scheme

291 employed here for grasslands could be applied equally to assess and monitor dynamics of any

292 other land cover type, i.e., fragmentation of forests or agricultural land.

\section{ACKNOWLEDGEMENTS}

294 We wish to acknowledge Professor Mariana Oyarzabal, Luciano Gandini and Maximiliano

295 Gandini for their contribution in english grammar revision. Also we want to thank Dr. Vilma

296 Manfreda for her critical reading of the different versions of the manuscript. A special thanks to

297 Dr. Peter Vogt, who has helped us increase the quality of this manuscript.

298 BIBLIOGRAPHY 
299 Baldi G, Texeira M, Martin OA, Grau HR, and Jobbágy EG. 2017. Opportunities drive the

300 global distribution of protected areas. PeerJ 5:e2989. 10.7717/peerj.2989

301 Bilenca D. F. Miñarro. 2004. Identificación de áreas valiosas de pastizal (AVPs) en las pampas

302 y campos de Argentina, Uruguay y sur de Brasil. 1a. ed. Fundación Vida Silvestre. Buenos

303 Aires, Argentina.

304 Cañibano M.A. M.L. Gandini M. B. Sacido. 2004. Evaluación de la intensificación del uso de la 305 tierra, en la cuenca del Arroyo del Azul, Buenos Aires, Argentina. Proceedings XI Simposio

306 Latinoamericano de percepción remota. Santiago, Chile.

307 Chander, G. B., Markham, L. Helder, D.L. (2009): Summary of current radiometric calibration

308 coefficients for Landsat MSS, TM, ETM+, and EO-1 ALI sensors. Remote Sensing of

309 Environment, 113, 893-903. DOI: 10.1016/j.rse.2009.01.007

310 Chapin F.S., Zavaleta E.S., Eviner V.T., Naylor R.L., Vitousek P.M., Reynolds H.L., Hooper D.

311 U., Lavorel, S. Sala, O. E. Hobbie S. E., Mack M. C., Díaz, S., 2000. Consequences of changing

312 biodiversity. Nature. 405:234-242. DOI: $10.1038 / 35012241$

313 Chavez, Jr. P. 1996: Image-based atmospheric correction- Revisited and improved

314 Photogrammetric Engineering and Remote Sensing, 2 (9), 1025-1036.

315 Chuvieco, E. 2010. Teledetección ambiental. Madrid, Editorial Ariel.

316 Clerici, N. \& Vogt P. 2013. Ranking European regions as providers of structural riparian

317 corridors for conservation and management purposes. International Journal of Applied Earth

318 Observation and Geoinformation 21(0): 477-483. DOI: 10.1016/j.jag.2012.07.001

319 Congalton, R. G. 1991: A review of assessing the accuracy of classifications of remotely sensed

320 data. Remote Sensing of Environment, 37, 35-46. DOI: 10.1016/0034-4257(91)90048-B

321 Crooks, K. R. \& Sanjayan, M. 2006. Connectivity conservation. Cambridge Univ. Press. DOI: 
322

323

324

325

326

327

328

329

330

331

332

333

334

335

336

337

338

339

340

341

342

343

344

\subsection{7/CBO9780511754821}

Díaz S, \& Cabido M. 2001. Vive la différence: plant functional diversity matters to ecosystem processes. Trends in Ecology and Evolution 16:646-655.4. DOI: 10.1016/S0169$5347(01) 02283-2$

Fahrig L. 2003. Effects of habitat fragmentation on biodiversity. Annual Review of Ecology Evolution and Systematics 34:487-515. DOI: 10.1146/annurev.ecolsys.34.011802.132419

Foley JA, Defries R, Asner GP, Barford C, Bonan G, Carpenter SR Chapin FS, Coe MT, Daily GC, Gibbs HK, Helkowski JH, Holloway T, Howard EA, Kucharik CJ, Monfreda C, Patz JA, Prentice IC, Ramankutty N, Snyder PK. 2005. Global consequences of land use. Science 309:570-574 DOI: 10.1126/science.1111772

Frangi, J. 1986. Sinopsis de las comunidades vegetales y el medio de las Sierras de Tandil.

Boletín de la Sociedad Argentina de Botánica (Argentina) 16(4): 293-319.

Gandini M., Lara B. \& Scaramuzzino R. 2014. Zonificación basada en la respuesta de ecosistemas a oscilaciones climáticas. Revista estudios Ambientales (Argentina) Vol 2:2 4-24. Harrington, R.; Dawson, T.P; de Bello, F.; Feld, C.K.; Haslett, J.R.; Kluvánkova-Oravská, T.; Kontogianni, A.; Lavorel, S.; Luck, G.W.; Rounsevell, M.D.A.; Samways, M.J.; Skourtos, M.; Settele, J.; Spangenberg, J.H.; Vandewalle, M.; Zobel, M. and P.A. Harrison. 2010. Ecosystem services and biodiversity conservation: concepts and a glossary. Biodiversity and Conservation 19: 2773-2790. DOI: 10.1007/s10531-010-9834-9

Henle, K., Lindenmayer, D.B., Margules, C.R. Saunders D.A., Wissel C. 2004. Species Survival in Fragmented Landscapes: Where are We Now? Biodiversity and Conservation13:1. DOI: 10.1023/B:BIOC.0000004311.04226.29

Herrera L., P. Laterra, N. Maceira, K. Zelaya y G. Martínez. 2009. Fragmentation status of tall- 
345 tussock grassland relicts in the FloodingPampa, Argentina. Rangeland Ecology and

346 Management62: 73-82. DOI: $10.2111 / 08-015$

347 Herrera, L.P. M. Texeira \& J.M. Paruelo 2012 Fragment size, vegetation structure and physical

348 environment control grassland functioning: a test based on artificial neural networks. Applied

349 Vegetation Science DOI: 10.1111/avsc.12009

350 Hobbs, R. J. \& Yates, C.J. (2003). Turner Review $\mathrm{N}^{\circ} 7$ - Impacts of ecosystem fragmentation on

351 plant populations: generalising the idiosyncratic. CSIRO Publishing, 2003.

352 oai:researchrepository.murdoch.edu.au: 16780

353 Keller J.K. \& C.R. Smith, Improving GIS-based Wildlife-Habitat Analysis,Springer Briefs in

354 Ecology, DOI: 10.1007/978-3-319-09608-7

355 Lara B. \& M. Gandini. 2011. Biogeografía de islasen fragmentos de pajonal del Paisaje

356 Ariel(Azul, Buenos Aires, Argentina). Revista AsociaciónArgentina de Ecología de Paisajes 2:

$357 \quad 1-8$.

358 Lara, B \& M Gandini. 2013a. Nuevo aporte para la distribución del Paspaletum en el centro de la

359 provincia de Buenos Aires. Revista AsociaciónArgentina de Ecología de Paisajes 4:1-12.

360 Lara B. \& M. Gandini. 2013b. Subdivisión de paisajes basada en aspectos funcionales de

361 laPampa Deprimida. Revista de la Facultad de Agronomía UNL-Pam 22(Supl.2): 93-98.

362 Lara, B. \& M. Gandini 2014. Quantifying the land cover changes and fragmentation patterns in

363 the Argentina Pampas, in the last 37 years (1974-2011). GeoFocus(Artículos), 14:163-180.

364 Laterra P. 2003. Desde el Paspaletum: bases ecológicas para el manejo de pajonales húmedos

365 con quemas prescriptas. En: Fuegoen los ecosistemas argentinos (C.R. Kunt, S. Bravo \& J.L.

366 Panigatti eds.).EdicionesINTA, Santiago del Estero, Argentina.

367 Lu, D. \& Weng, Q. 2007. A survey of image classification methods and techniques for 
368 improving classification performance. International Journal of Remote Sensing 26 (5), 823-870.

369 DOI: $10.1080 / 01431160600746456$

370 Maguire D.Y., Buddle C.M., Bennett E.M. (2016) Within and Among Patch Variability in

371 Patterns of Insect Herbivory Across a Fragmented Forest Landscape. PLoS ONE 11(3):

372 e0150843. DOI: 10.1371/journal.pone.0150843

373 Mitchell M.G.E., Bennett E.M., Gonzalez A. 2014. Forest fragments modulate the provision of

374 multiple ecosystem services. Journal of Applied Ecology; 51:909-918 DOI: 10.1111/1365-

$375 \quad 2664.12241$

376 Perelman S.; Burkart S., León R., 2003. The role of a native tussock grass (Paspalum

377 quadrifarium Lam.) in structuring plant communities in the Flooding Pampa grasslands,

378 Argentina. Biodiversity and Conservation 12: 225-238. DOI: 10.1023/A:1021948723714

379 Pontius, R. G. \& M. Millones (2011): "Death to Kappa: birth of quantity disagreement and

380 allocation disagreement for accuracy assessment”, Intl Journal of Remote Sensing, 32 (15),

381 4407-4429. DOI: 10.1080/01431161.2011.552923

382 QGIS Development Team. 2018. QGIS Geographic Information System. Open Source

383 Geospatial Foundation Project. Website: http://qgis.osgeo.org

384 Saura, S. and Torné, J. (2009). Conefor Sensinode 2.2: a software package for quantifying the

385 importance of habitat patches for landscape connectivity. Environmental Modelling \& Software

386 24: 135-139.DOI: 10.1016/j.envsoft.2008.05.005

387 Saura S, Vogt P, Velázquez J, Hernando A, Tejera R. 2011. Key structural forest connectors can

388 be identified by combining landscape spatial pattern and network analyses. Forest Ecology and

389 Management 262 (2011) 150-160. DOI: 10.1016/j.foreco.2011.03.017

390 Schulz, J. J., L. Cayuela, C. Echeverría, J. Salas \& J. M. Rey Benayas 2010. Monitoring land 
391 cover change of the dryland forest landscape of Central Chile (1976-2008) Applied Geography

39230 436-447. DOI: 10.1016/j.apgeog.2009.12.003

393 Seebach, L., Strobl, P., Vogt, P., Mehl, W., San-Miguel-Ayanz, J. (2013) Enhancing post-

394 classification change detection through morphological post- processing - a sensitivity analysis.

395 International Journal of Remote Sensing, 34 (20), 7145-7162. DOI:

$396 \quad 10.1080 / 01431161.2013 .815382$

397 Soille P. \& Vogt P. 2008. Morphological segmentation of binary patterns. Pattern Recognition

398 Letters 30, 4:456-459 DOI: 10.1016/j.patrec.2008.10.015

399 Turner M.G, \& R.H. Gardner, 2015 Landscape Ecology in Theory and Practice, Springer-Verlag

400 New York DOI: 10.1007/978-1-4939-2794-4_6.

401 Taylor, P. D., L. Fahrig, K. Henein, G. Merriam. 1993. Connectivity is a vital element of 402 landscape structure. Oikos 68:571-573.

403 Vazquez P., L. Zulaica \& E. Requesens. 2012. Análisis del proceso de agriculturización enel

404 partido de Azul (provincia de BuenosAires), mediante el uso de sensores remotos (1984-2011).

405 Actas del Congreso Argentino de Teledetección. Córdoba, Argentina.

406 Vervoorst, FB. 1967. Las comunidades vegetales de la Depresión del Salado (Provincia de

407 Buenos Aires). La vegetación de la República Argentina. Serie Fitogeográfica 7, INTA. Buenos

408 Aires, $262 \mathrm{pp}$.

409 Vitousek P. M., H. A. Mooney; J. Lubchenco; J. M. Melillo, 1997. Human Domination of Earth's

410 Ecosystems. Science New Series, Vol. 277, N 5325 pp. 494-499. DOI:

$4110.1126 /$ science.277.5325.494/

412 Vogt P. \& Riitters, K, 2017. GuidosToolbox: universal digital image object analysis. European

413 Journal of Remote Sensing, 50, 1, pp. 352-361, DOI: $\underline{10.1080 / 22797254.2017 .1330650}$ 
414 Vogt, P., Riitters, K.H., Estreguil, C. Kozak J, Wade TG, Wickham JD. 2007a.Mapping Spatial

415 Patterns with Morphological Image Processing. Landscape Ecology 22: 171. 10.1007/s 10980-

$416 \quad 006-9013-2$

417 Vogt, P, Riitters, K, Iwanowski, M, Estreguil, C, Kozak, J, Soille, P. 2007b. Mapping landscape

418 corridors. Ecological Indicators. 7. 481-488. DOI: 10.1016/j.ecolind.2006.11.001/

419 Vogt P, 2014. GuidosToolbox (Graphical User Interface for the Description of Image Objects

420 and their Shapes): Digital image analysis software collection available online:

421 http://forest.jrc.ec.europa.eu/download/software/guidos

422 Volante, J.N. D. Alcaraz-Segura, M.J. Mosciaro, E.F. Viglizzo, J.M. Paruelo, 2012. Ecosystem

423 functional changes associated with land clearing in NW Argentina,Agriculture, Ecosystems \&

424 Environment, Volume 154:12-22, DOI: 10.1016/j.agee.2011.08.012

425 White PS, \& Jentsch A (2001) The search for generality in studies of disturbance and

426 ecosystemdynamics. Progress in Botany 62:399-450

427 Wickham, J D, Riitters KH, Wade T G, Vogt P, 2010. A national assessment of green

428 infrastructure and change for the conterminous United States using morphological image

429 processing. Landscape and Urban Planning 94, 186-195. DOI:

$430 \quad 10.1016 /$ j.landurbplan.2009.10.003

431 Wilson, M.C., Chen, XY., Corlett, R.T. Didham R. K., P. Ding, R.D. Holt, M. Holyoak, G. Hu, 432 A.C. Hughes, L. Jiang, W.F. Laurance, J. Liu, S.L. Pimm, S.K. Robinson, S.E. Russo, X. Si,

433 D.S. Wilcove, J. Wu, M. Yu. 2016 Habitat fragmentation and biodiversity conservation: key

434 findings and future challenges. Landscape Ecology (2016) 31: 219. DOI: 10.1007/s10980-015-

$435 \quad 0312-3$

436 Woods LM, Biro EG, Yang M, Smith KG. (2016) Does regional diversity recover after 
437 disturbance? A field experiment in constructed ponds. PeerJ 4:e2455 DOI: 10.7717/peerj.2455/

438 Ziter C, Bennett EM, Gonzalez A. 2013. Functional diversity and management mediate

439 aboveground carbon stocks in small forest fragments. Ecosphere. 4: art85.6 DOI:10.1890/ES13-

$440 \quad 00135.1 /$

441 


\section{Table $\mathbf{1}$ (on next page)}

Classification quality of Pq cover estimation, and numerical results of the morphological and connectivity analysis.

Most significant MSPA results (as percentages over the total) and connectivity analysis:

Number of components, maximum, mean and median of connectors / component; and relative ECA 
1

\begin{tabular}{lllllll} 
Analysis & Parm/Form/year & 1974 & 1988 & 2000 & 2011 & 2016 \\
\hline Class. Disagreement \% (PJ) & Quantity & 1 & 5 & 5 & 4 & 2 \\
& Allocation & 10 & 18 & 12 & 9 & 12 \\
\hline MSPA & Core (small) & 4.04 & 3.12 & 3.68 & 3.17 & 3.46 \\
& Core (medium) & 4.43 & 2.08 & 3.12 & 2.85 & 2.17 \\
\cline { 2 - 6 } & Core (large) & 16.95 & 4.58 & 6.06 & 3.73 & 3.71 \\
& Islet & 0.85 & 2.53 & 1.11 & 1.46 & 1.75 \\
\cline { 2 - 6 } & Perforation & 2.97 & 0.73 & 0.60 & 0.30 & 0.57 \\
\cline { 2 - 6 } & Edge & 17.06 & 9.87 & 11.13 & 8.61 & 10.72 \\
\hline Loop & 0.19 & 0.40 & 0.27 & 0.14 & 0.20 \\
\hline Foreground Area & Bridge & 0.46 & 2.24 & 1.11 & 0.73 & 0.77 \\
(links) & Branch & 1.91 & 3.24 & 2.35 & 2.13 & 2.31 \\
\hline & \# pixels & 7878004 & 4641009 & 4745490 & 3728019 & 4135826 \\
\hline & Mean of links & 1153 & 379 & 287 & 167 & 49 \\
& median of links & 55 & 49 & 41 & 21 & 43 \\
& max links & 80557 & 28468 & 16738 & 15040 & 43912 \\
& ECA (pixels) & 945277 & 894122 & 1041192 & 236552 & 374184 \\
& relative ECA \% & 28 & 57 & 50 & 15 & 25
\end{tabular}

2 
Figure 1

Study area and agroecological zones

Study area and its location in the province of Buenos Aires, Argentina and South America.

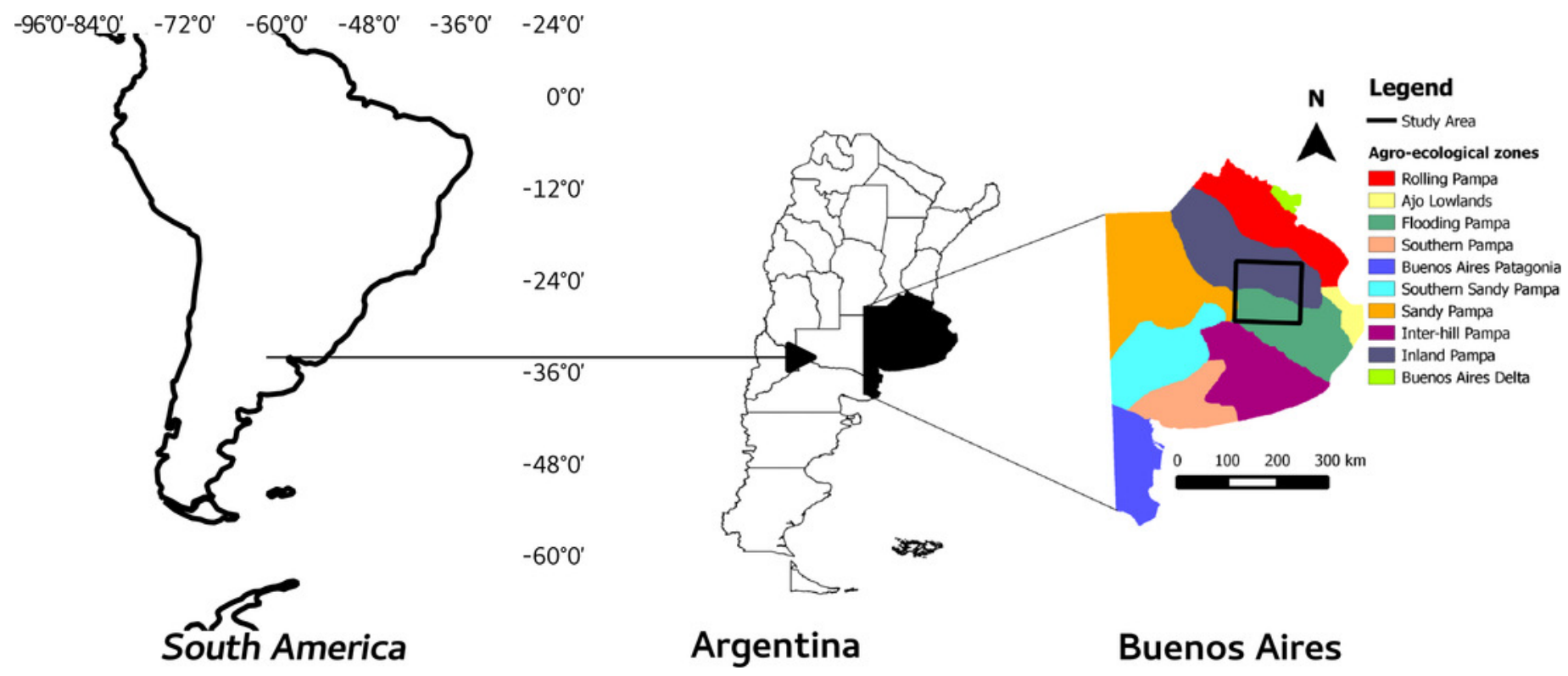


Figure 2

MSPA results for 1974

Results showing start (1974) of Pq grassland status. In different colors, core areas and another morphological elements obtained by MSPA (see references) Background areas in grey

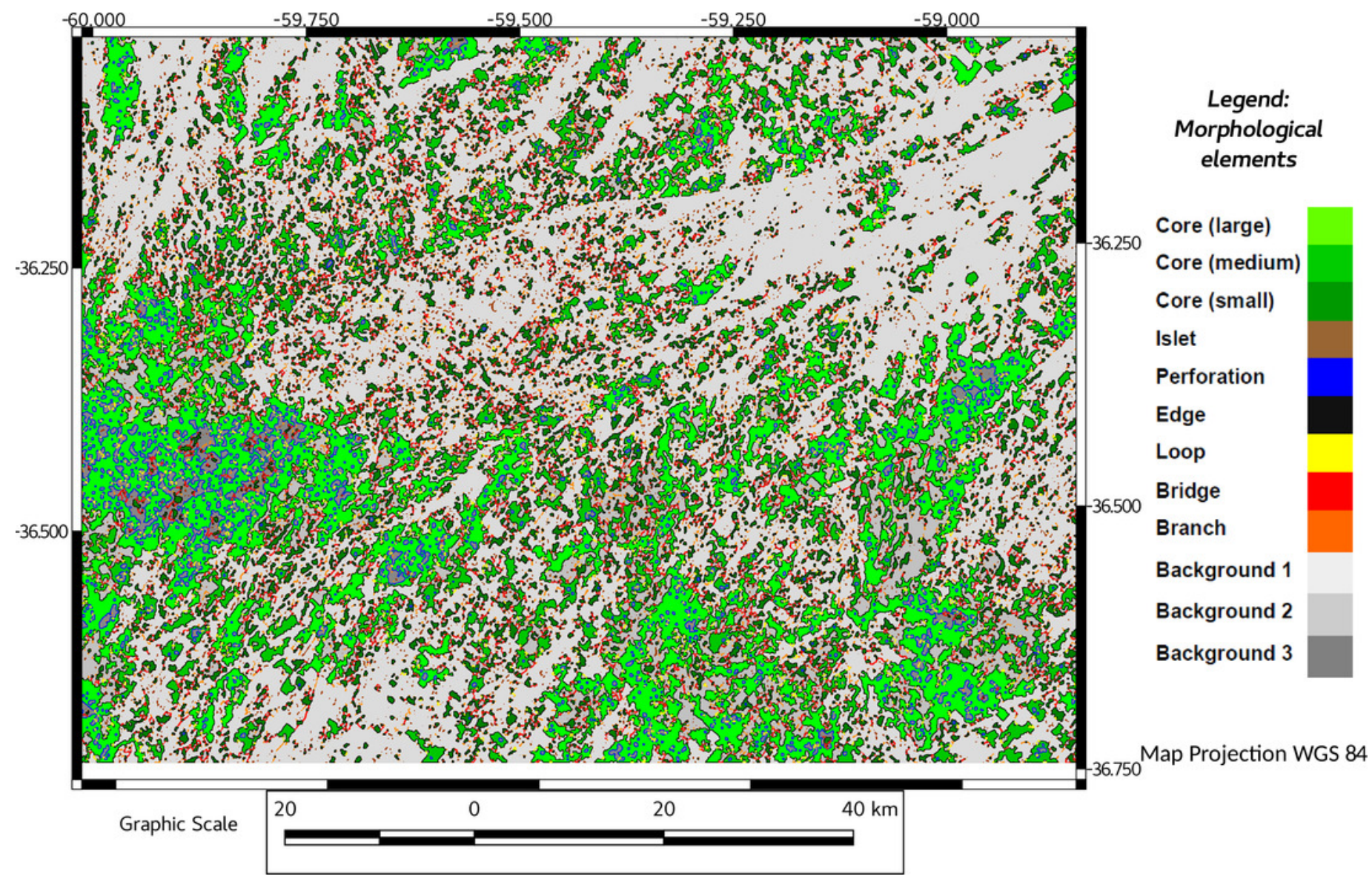


Figure 3

MSPA results for 2016

Results showing end (2016) of Pq grassland status. In different colors, core areas and another morphological elements obtained by MSPA. Background areas in grey (not discussed)

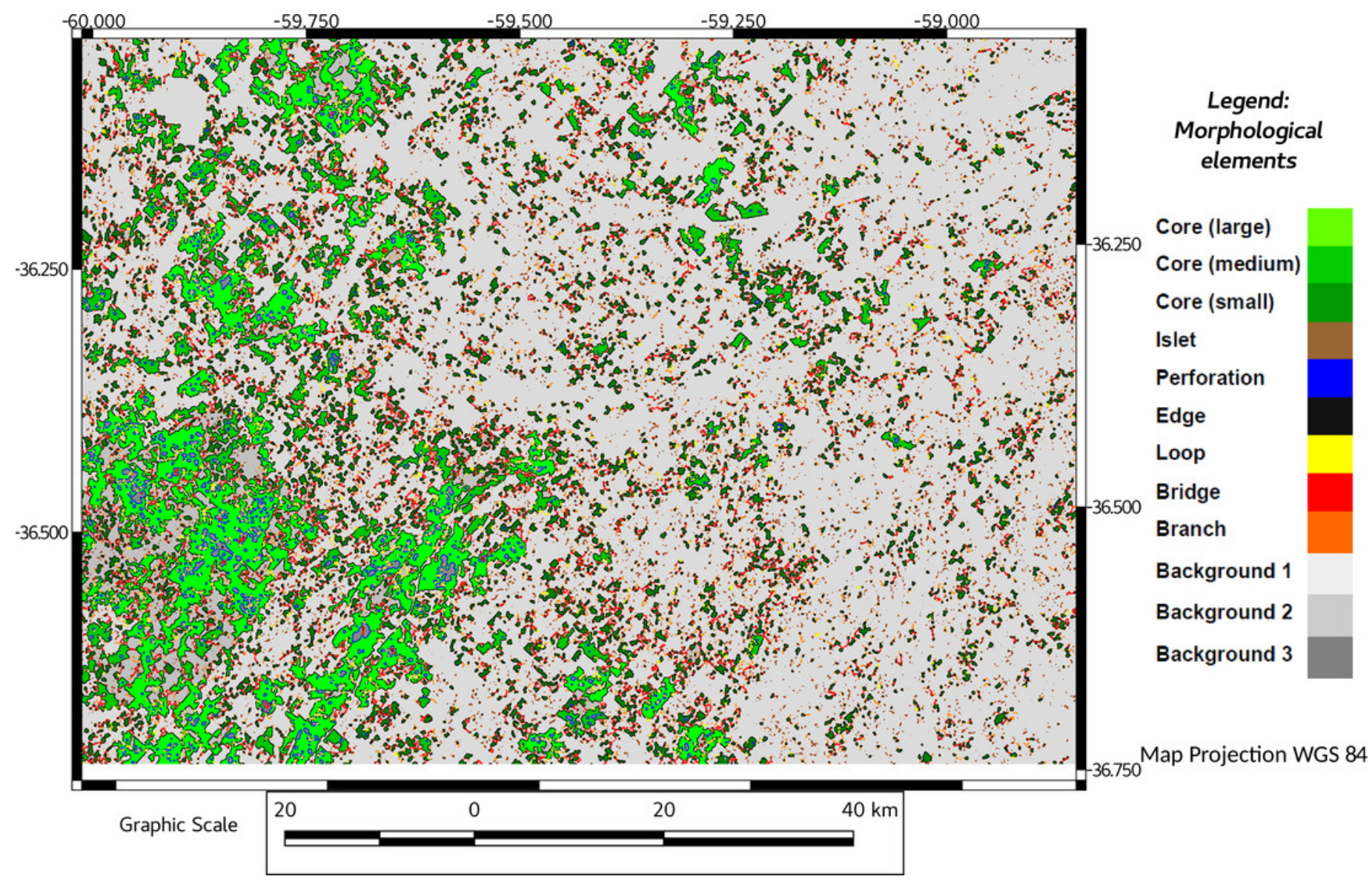


Figure 4

Network connectivity results for start of period of study (1974)

Objects belonging to the same network are represented with the same color.

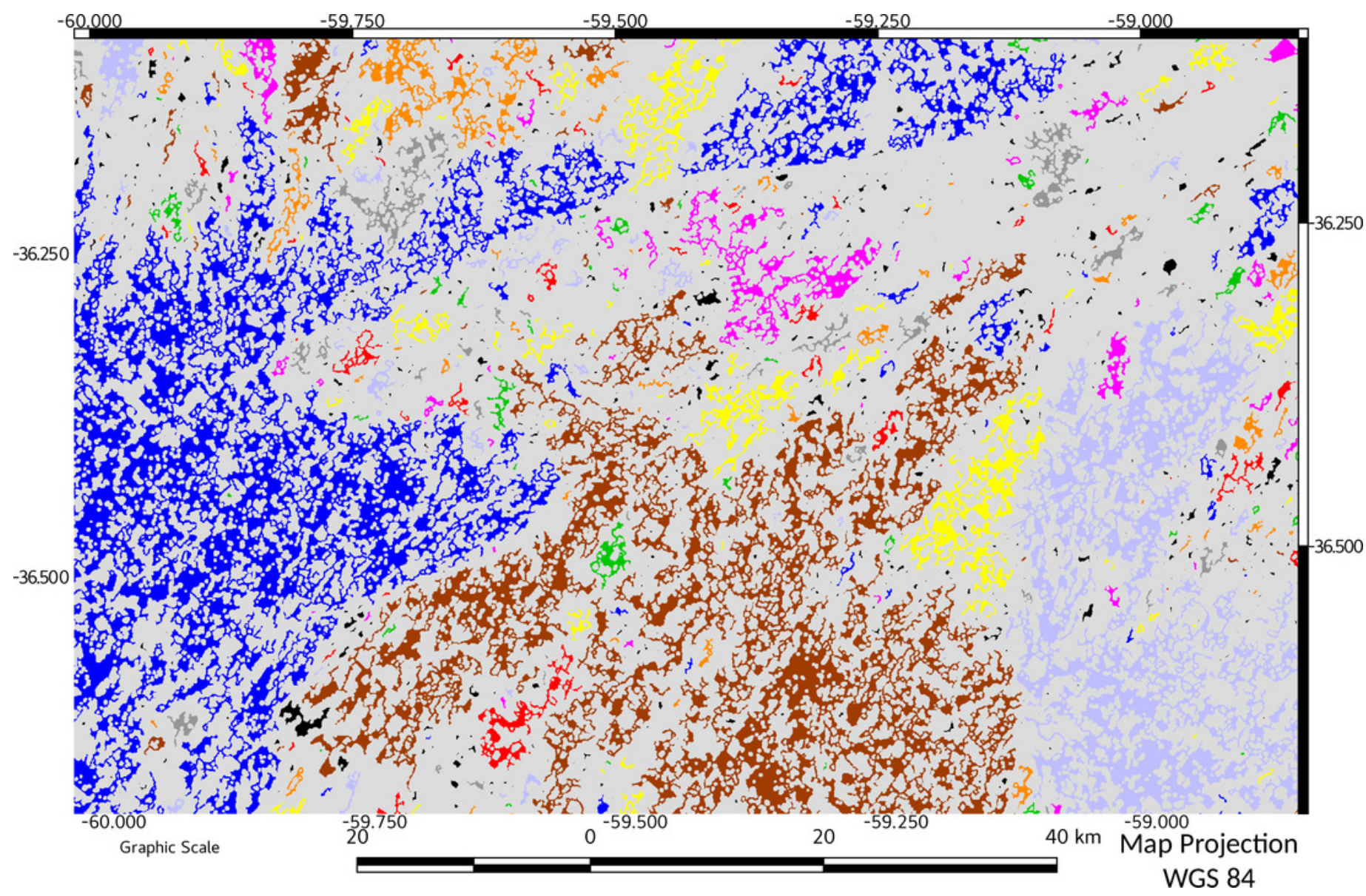


Figure 5

Network connectivity results for end of period of study (2016)

Objects belonging to the same network are represented with the same color. A comparison with Figure 4 can spatially indicate the relevance of the change in connectivity.

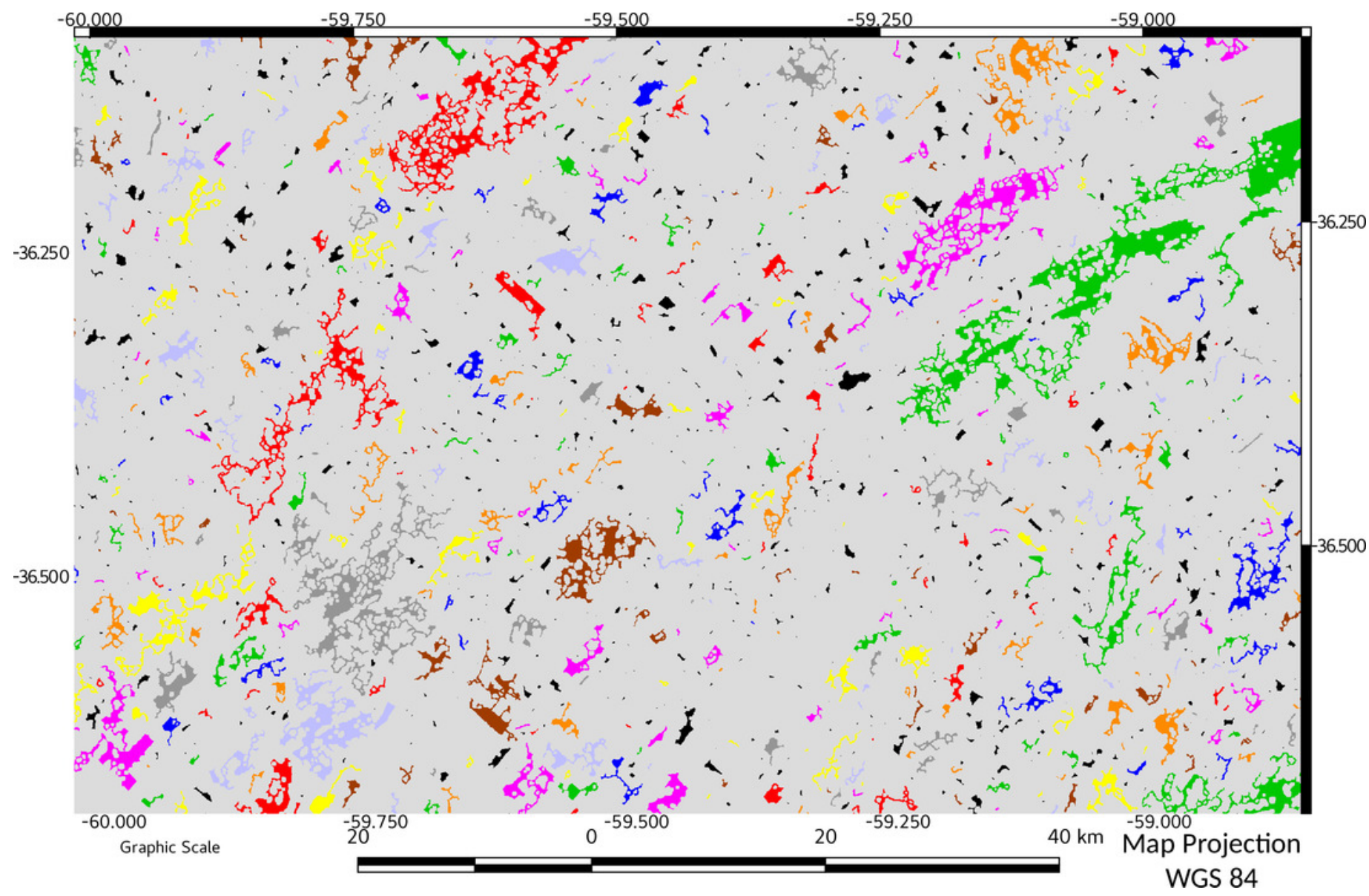




\section{Figure 6}

Morphological Change Detection between 1974 and 2016

Results of applying MCD to data from start and end of study period. Pixels in red indicate loss of foreground area, and green indicate gains. A foreground loss of $43 \%$ is explained mainly as internal foreground loss (elasticity 1.10575) Dark grey indicate unchanged foreground area.

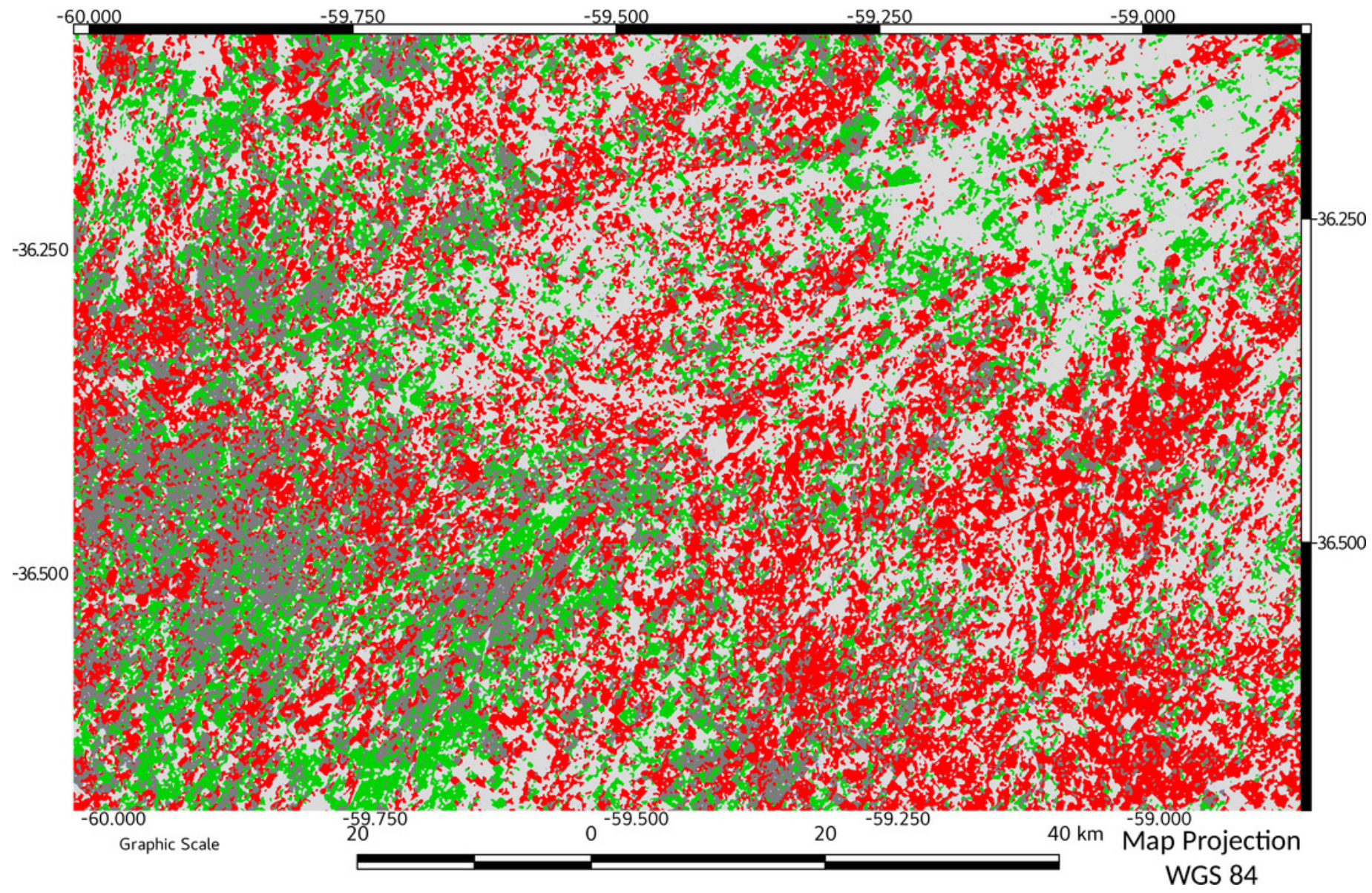

